\title{
Localization of HCN1 Channels to Presynaptic Compartments: Novel Plasticity That May Contribute to Hippocampal Maturation
}

\author{
Roland A. Bender, ${ }^{1 *}$ Timo Kirschstein, ${ }^{2 \star}$ Oliver Kretz, ${ }^{3}$ Amy L. Brewster, ${ }^{1}$ Cristina Richichi, ${ }^{1}$ \\ Christiane Rüschenschmidt, ${ }^{4}$ Ryuichi Shigemoto, ${ }^{5}$ Heinz Beck, ${ }^{4}$ Michael Frotscher, ${ }^{3}$ and Tallie Z. Baram ${ }^{1}$ \\ ${ }^{1}$ Departments of Anatomy, Neurobiology, and Pediatrics, University of California, Irvine, Irvine, California 92697-4475, ${ }^{2}$ Department of Physiology, \\ University of Rostock, D-18055 Rostock, Germany, ${ }^{3}$ Institute of Anatomy and Cell biology, University of Freiburg, D-76104 Freiburg, Germany, \\ ${ }^{4}$ Department Epileptology, University of Bonn, Medical Center, D-53105 Bonn, Germany, and 5 Division of Cerebral Structure, National Institute for \\ Physiological Sciences, Myodaiji, Okazaki 444-8787, Japan
}

Increasing evidence supports roles for the current mediated by hyperpolarization-activated cyclic nucleotide-gated (HCN) channels, $I_{\mathrm{h}}$, in hippocampal maturation and specifically in the evolving changes of intrinsic properties as well as network responses of hippocampal neurons. Here, we describe a novel developmental plasticity of $\mathrm{HCN}$ channel expression in axonal and presynaptic compartments: HCN1 channels were localized to axon terminals of the perforant path (the major hippocampal afferent pathway) of immature rats, where they modulated synaptic efficacy. However, presynaptic expression and functions of the channels disappeared with maturation. This was a result of altered channel transport to the axons, because HCN1 mRNA and protein levels in entorhinal cortex neurons, where the perforant path axons originate, were stable through adulthood. Blocking action potential firing in vitro increased presynaptic expression of HCN1 channels in the perforant path, suggesting that network activity contributed to regulating this expression. These findings support a novel developmentally regulated axonal transport of functional ion channels and suggest a role for HCN1 channel-mediated presynaptic $I_{\mathrm{h}}$ in hippocampal maturation.

Key words: ion channel; entorhinal cortex; synaptic plasticity; development; perforant path; neuronal activity

\section{Introduction}

The developmental organization of the hippocampal network is governed by both genetic and environmental elements. In addition to established roles for transcription factors (Liu et al., 2000; Knoll et al., 2006) and guidance molecules (Skutella and Nitsch, 2001; Förster et al., 2006), activity is a key determinant of network organization (Constantine-Paton and Cline, 1998): in the neonatal hippocampus, intrinsically generated synchronized network activity provides a stimulus for neuronal differentiation and the maturation of network connectivity (Ben-Ari, 2002). Once connections among neurons are established, activity is essential for their fine tuning (Frotscher et al., 2000; Galvan et al., 2003). Molecules that regulate activity patterns in neurons, including ion channels, contribute critically to these processes.

A family of ion channels that has recently been implicated in

Received 0ct. 28, 2006; revised March 21, 2007; accepted March 22, 2007.

This work was supported by National Institutes of Health Grants NS35439 (T.Z.B.) and T32 NS045540 (A.L.B.), Epilepsy Foundation of America (R.A.B.), and Deutsche Forschungsgemeinschaft (Transregio-SFB TR-3; M.F. and H.B.). We thank Drs. Y. Chen and E. C. Cooper for helpful advice, N. Patel and B. Joch for excellent technical help, and M. Hinojosa for editorial assistance.

*R.A.B and T.K. contributed equally to this work.

Correspondence should be addressed to Dr. Roland A. Bender, Institute of Anatomy I, University of Hamburg, D-20246 Hamburg. E-mail: r.bender@uke.uni-hamburg.de.

DOI:10.1523/JNEUROSCI.4699-06.2007

Copyright $\odot 2007$ Society for Neuroscience $\quad$ 0270-6474/07/274697-10\$15.00/0 hippocampal organization are the hyperpolarization-activated cyclic nucleotide-gated $(\mathrm{HCN})$ channels, that generate current, $I_{\mathrm{h}}$ (Kaupp and Seifert, 2001; Robinson and Siegelbaum, 2003). In the hippocampus, expression of $\mathrm{HCN}$ channel isoforms is developmentally regulated (Bender et al., 2001; Vasilyev and Barish, 2002; Brewster et al., 2007), resulting in age-specific cellular complements of HCN channels and $I_{\mathrm{h}}$ properties (Vasilyev and Barish, 2002; Surges et al., 2006). These contribute to the generation of age-specific patterns of neuronal activity (Agmon and Wells, 2003; Bender et al., 2005). Neuronal activity, in turn, selectively modulates the expression of specific HCN channel isoforms (Brewster et al., 2002, 2005; Santoro and Baram, 2003), thus governing the properties of $I_{\mathrm{h}}$ and, consequently, the excitability of hippocampal neurons (Chen et al., 2001).

The function of HCN channels depends on their expression levels as well as their subcellular localization (Magee, 1998; Poolos et al., 2002; Santoro and Baram 2003; Aponte et al., 2006). For example, dendritic HCN channels control integration and temporal summation of synaptic input to CA1 pyramidal cells (Magee, 1998; Poolos et al., 2002), whereas somatic HCN channels contribute to cell properties such as the regulation of resting membrane potential (Maccaferri and McBain, 1996; Lupica et al., 2001; Nolan et al., 2004). Recently, axonal HCN channels have been detected in certain hippocampal neuron populations (Soleng et al., 2003; Notomi and Shigemoto, 2004; Aponte et al., 
2006; Brewster et al., 2007), although their function remains unclear.

Here, we report on a novel axonal localization of HCN channels in the perforant path that occurs only during development: we initially found that channels of the HCN1 subtype were expressed in the termination zone of perforant path fibers in the dentate gyrus (DG) of immature rats. Fine-structural analysis and disconnection studies revealed a presynaptic localization of these channels that was further supported by electrophysiological approaches demonstrating a contribution of $I_{\mathrm{h}}$ to the firing properties of the immature perforant path. Whereas HCN1 mRNA and protein levels in the cells of origin in the entorhinal cortex (EC) did not decrease with age, expression of HCN channel molecules in axonal and presynaptic compartments was attenuated, suggesting that the transport of $\mathrm{HCN} 1$ channels to perforant path axons changed with age. Further, blocking action potential firing increased presynaptic $\mathrm{HCN} 1$ channel expression, suggesting that network activity is involved in regulating axonal expression of the HCN1 channel.

\section{Materials and Methods}

Animals. Sprague Dawley-derived pregnant dams were maintained in a federally approved animal facility. Animals were housed in a quiet, uncrowded room under a $12 \mathrm{~h}$ light/dark cycle (lights on at 7:00 A.M.) with ad libitum access to food and water. Delivery was verified at $12 \mathrm{~h}$ intervals (date of birth, day 0). On postnatal day 2 (P2), litters were adjusted to 12 pups. When weaned (on P21), rats were housed 2-3 per cage. Homozygous HCN1-deficient (Strain B6; 129-Hcn1 < tm2Kndl>/J) and wildtype mice (B6129SF2/J) were purchased from The Jackson Laboratory (Bar Harbor, ME), and then maintained and bred under standard conditions. All experimental procedures were approved by the University of California, Irvine, Animal Care Committee and were in accordance with National Institutes of Health guidelines.

Immunocytochemistry. Rats of different ages (P3, P11, P15, P21, P25, $\mathrm{P} 35, \mathrm{P} 90 ; n=3$ each) or mice (P11; $n=2$ for each genotype) were deeply anesthetized with sodium pentobarbital (100 mg/kg, i.p.) and transcardially perfused with $4 \%$ phosphate-buffered paraformaldehyde (PFA). Brains were removed, postfixed in 4\% PFA for $4 \mathrm{~h}$, cryoprotected in $25 \%$ sucrose for 24-72 h, and frozen in isopentane. Horizontal sections (40 $\mu \mathrm{m}$ ) were cut on a cryostat and collected in PBS. Sections were treated for 20 min with $0.3 \% \mathrm{H}_{2} \mathrm{O}_{2} / \mathrm{PBS}$, washed three times for $10 \mathrm{~min}$ in PBS and $0.3 \%$ Triton X-100 (PBS-T), and preincubated for $1 \mathrm{~h}$ with $10 \%$ normal goat serum/PBS-T, followed by incubation with primary antisera for $48 \mathrm{~h}$ at $4^{\circ} \mathrm{C}$. The following antisera were used: polyclonal rabbit anti-HCN1 (1:2500; Millipore, Bedford, MA), polyclonal guinea pig anti-HCN1 (1: $500)$, anti-HCN2 (1:1500), or anti-HCN4 (1:800) (Notomi and Shigemoto, 2004). Rabbit- and guinea pig-derived $\mathrm{HCN} 1$ antisera produced identical results. After primary antibody incubation and several washes, sections were transferred to secondary antibody solution (biotinylated goat anti-rabbit or goat anti-guinea pig IgGs, 1:250; Vector Laboratories, Burlingame, CA) for $3 \mathrm{~h}$, followed by additional washes and avidinbiotin-peroxidase complex solution (Vector Laboratories) for $2 \mathrm{~h}$ at room temperature. Antibody binding was visualized by incubating sections in a solution containing $0.04 \% 3,3^{\prime}$ diaminobenzidine, $0.01 \%$ $\mathrm{H}_{2} \mathrm{O}_{2}, 0.01 \% \mathrm{NiCl}_{2}$, and $0.01 \% \mathrm{CoCl}_{2}$. Control experiments included treatment of sections as above but with primary antibodies omitted. No immunoreactivity was observed under these conditions. Antigen specificity of the two different $\mathrm{HCN} 1$-antisera used in this study was further tested with hippocampal sections derived from HCN1-deficient $(-/-)$ mice. No HCN1-signal was detected in these mice (see Fig. $2 b$ ), whereas $\mathrm{HCN} 1$ distribution in wild-type mice was very similar to that observed in rats of the corresponding age (see Fig. $2 a$ ).

In situ hybridization. For quantitative radioactive in situ hybridization, rats (P11 and P90; $n=4$ each) were decapitated, and brains rapidly dissected and frozen in powdered dry ice. Brains were then cut on a cryostat, sections $(20 \mu \mathrm{m})$ mounted to slides and hybridized as described previously, using antisense ${ }^{35} \mathrm{~S}$-cRNA probes synthesized by in vitro tran- scription from cDNAs containing specific regions of the mouse HCN1 gene (Brewster et al., 2002, 2007). Nonradioactive in situ hybridization was performed on brain sections from transcardially perfused rats (see above) using digoxigenin-labeled probes as described by Bender et al. (2001).

Western Blots. For Western blot analysis, immature (P11) or adult rats (P90; $n=6$ for each group) were rapidly decapitated, and ECs were quickly dissected and immediately frozen in dry ice. Tissue was then homogenized in glass/Teflon homogenizers in ice-cold $0.32 \mathrm{~m}$ sucrose, $0.1 \mathrm{M}$ Tris- $\mathrm{HCl}, \mathrm{pH} 7.4$, containing protease inhibitor mixture (PIC Complete; diluted according to manufacturer's instructions; Roche, Alameda, CA). Samples were centrifuged at $1000 \times g$ for $10 \mathrm{~min}$ at $4^{\circ} \mathrm{C}$, and the pellet was discarded. The resulting supernatant was centrifuged at $16,000 \times g$ for $20 \mathrm{~min}$ at $4^{\circ} \mathrm{C}$, and the pellet containing membrane fractions was resuspended in artificial CSF (aCSF) containing the following: $124 \mathrm{~mm} \mathrm{NaCl}, 3 \mathrm{~mm} \mathrm{KCl}, 1.25 \mathrm{~mm} \mathrm{KH_{2 }} \mathrm{PO}_{4}, 2.5 \mathrm{~mm} \mathrm{MgSO}$, $3.4 \mathrm{~mm}$ $\mathrm{CaCl}_{2}, 26 \mathrm{~mm} \mathrm{NaHCO}_{3}, 10 \mathrm{~mm}$ D-glucose, $\left.1 \times \mathrm{PIC}\right)$. Protein concentration was determined using the Bio-Rad Protein Assay (Bio-Rad, Hercules, CA). Equal amounts of protein were diluted in Laemmli buffer. Protein extracts $(30 \mu \mathrm{g})$ were then separated on a $4-12 \%$ SDS-PAGE and transferred to Hybond-P polyvinyl difluoride membranes (Amersham Biosciences, Piscataway, NJ). Membranes were blocked with $10 \%$ nonfat milk in $1 \times \mathrm{PBS}$ overnight at $4^{\circ} \mathrm{C}$ and were probed with rabbit anti-HCN1 (1:500; Millipore) or rabbit anti-actin antisera (1:40,000; Sigma, St. Louis, MO). After washes in PBS-1\% Tween (three times for $5 \mathrm{~min}$ ), membranes were incubated with secondary antibodies (donkey antirabbit IgG conjugated to horseradish peroxidase, 1:10,000; Amersham Biosciences) in PBS for $1 \mathrm{~h}$ at room temperature. Membranes were then washed again in PBS-1\% Tween (three times for $5 \mathrm{~min}$ ) and incubated with ECL-plus. Immunoreactive bands were visualized by apposing membranes to hyperfilm ECL.

Organotypic slice culture. Combined entorhinohippocampal slice cultures were prepared from 4-d-old rats and maintained using the interface technique (Stoppini et al., 1991; Chen et al., 2004). Briefly, pups were decapitated, and brains were removed and split into two hemispheres. Hippocampi with ECs attached were dissected and cut into perpendicular $400-\mu \mathrm{m}$-thick slices using a McIlwain tissue chopper. Slices were collected in ice-cold preparation buffer (100\% Minimal Essential Medium containing $30 \mathrm{~mm}$ glucose and $3 \mathrm{~mm}$ glutamine, $\mathrm{pH}$ 7.3) (Invitrogen, San Diego, CA), then placed onto moistened membrane inserts (Millicell-CM, $30 \mathrm{~mm}, 0.4 \mu \mathrm{m}$ pore diameter; Millipore), transferred to sterile six-well plates filled with $1 \mathrm{ml}$ of culture medium (50\% Minimal Essential Medium, 25\% HBSS, 20\% heat-inactivated horse serum, $30 \mathrm{~mm}$ HEPES, $30 \mathrm{~mm}$ D-glucose, $3 \mathrm{~mm}$ glutamine, $0.5 \mathrm{~mm}$ ascorbic acid, 1 $\mathrm{mg} / \mathrm{ml}$ insulin, $5 \mathrm{~mm} \mathrm{NaHCO}, \mathrm{pH} 7.3$ ) and incubated in a humidified, $\mathrm{CO}_{2}$-enriched atmosphere at $36^{\circ} \mathrm{C}$. To study the role of neuronal activity for the regulation of HCN1 transport, $0.1 \mu \mathrm{M}$ tetrodotoxin (TTX; Sigma) was added on the second day, and TTX-treatment was continued through the seventh day in vitro. The medium was changed every $2 \mathrm{~d}$. To minimize culture variability, pairs of adjacent slices (sister cultures) were always compared (i.e., one of each used for control and experimental conditions) ( $n=31$ for each group). For transection experiments, the EC and hippocampus were partially separated after $4 \mathrm{~d}$ in vitro by a knife cut in the experimental group, whereas sister cultures remained intact $(n=$ 12 for each group). For both the TTX- and the transection experiments, after $7 \mathrm{~d}$ in vitro cultures were fixed in 4\% PFA ( $2 \mathrm{~h})$, cryoprotected in $25 \%$ sucrose $(12 \mathrm{~h})$, and frozen on dry ice. Sections were cut on a cryostat and processed for immunocytochemistry or in situ hybridization as described above. Sections from experimental and control sister cultures were always processed concurrently.

Electron microscopy. For electron microscopy (EM), 10-d-old rats ( $n=$ 4 ) or mice ( $n=2$ for each genotype) were deeply anesthetized with an overdose of Narkodorm-n ( $250 \mathrm{mg} / \mathrm{kg}$ body weight) and transcardially perfused with $0.9 \%$ saline followed by a fixative containing $4 \%$ PFA and $0.1 \%$ glutaraldehyde in $0.1 \mathrm{~m}$ phosphate buffer, $\mathrm{pH} 7.4$. Brains were removed and postfixed in the same fixative for $12 \mathrm{~h}$. For pre-embedding $\mathrm{EM}$, tissue blocks were washed with phosphate buffer and horizontal sections $(50 \mu \mathrm{m})$ were cut on a vibratome. Sections were cryoprotected in a solution containing $25 \%$ sucrose and $10 \%$ glycerol (in $50 \mathrm{~mm}$ phos- 
phate buffer), then freeze-thawed and transferred to blocking solution containing $20 \%$ normal goat serum in $50 \mathrm{~mm}$ Tris-buffered saline (TBS) for $1 \mathrm{~h}$, followed by incubation with the primary antibody against HCN1 [rabbit anti-HCN1 (Millipore), 1:250; guinea pig anti-HCN1 (Notomi and Shigemoto, 2004), 1:50] in TBS for $7 \mathrm{~d}$ at $4^{\circ} \mathrm{C}$. After washing, sections were incubated either with biotinylated goat anti-rabbit IgG secondary antibody (1:50) for immunoperoxidase reaction or with $1.4 \mathrm{~nm}$ goldcoupled goat anti-rabbit (1:100; Nanogold; Nanoprobes, Stony Brook, $\mathrm{NV}$ ) or goat anti-guinea pig secondary antibodies (1:50; British BioCell International, Cardiff, UK) for immunogold detection. Immunoperoxidase sections were reacted with avidin-biotin-peroxidase complex solution and immunogold sections with the HQ silver kit (Nanoprobes). Sections were treated with $\mathrm{OsO} 4$, stained with uranyl acetate, dehydrated, and flat-embedded in epoxy resin (Durcupan ACM; Fluka, Gillingham, UK). Ultrathin sections were then cut, followed by examination in a Philips CM 100 electron microscope. For post-embedding immunogold EM, P10 rats $(n=2)$ were perfused and postfixed as described above. Brains were then cut on a vibratome into $300 \mu \mathrm{m}$ sections, and the DG of the hippocampus was excised. Tissue blocks were cryoprotected in glycerol, cryofixed in nitrogen-cooled propane, substituted in methanol containing 1.5\% uranyl acetate, and embedded in Lowicryl HM20 (Chemische Werke Lowi, Waldkraiburg, Germany). Ultrathin sections were processed for postembedding immunocytochemistry with the guinea pig-derived anti-HCN1 antibody (1:50) (Notomi and Shigemoto, 2004). Binding of the primary antibody was detected with a $10 \mathrm{~nm}$ gold-coupled anti-guinea pig secondary antibody (1:50; British BioCell International). Control sections lacking exposure to the primary antibody were included in the same incubation procedure. Examination was performed as described above.

Extracellular recordings. Animals were deeply anesthetized with diethyl ether, decapitated, and brains rapidly dissected. Horizontal hippocampal slices $(400 \mu \mathrm{m})$ were prepared using a 1000S Vibratome (Leica, Wetzlar, Germany) or Integraslice (Campden Instruments, Loughborough, UK) in ice-cold dissection fluid containing the following (in $\mathrm{mM}$ ): $125 \mathrm{NaCl}$, $25 \mathrm{NaHCO}_{3}, 3 \mathrm{KCl}, 1.25 \mathrm{NaH}_{2} \mathrm{PO}_{4}, 0.2 \mathrm{CaCl}_{2}, 5 \mathrm{MgCl}_{2}, 13$ D-glucose. All procedures were performed according to the guidelines of the Animal Care and Use Committee at the Universities of Bonn and Rostock. Slices were transferred into an interface chamber heated within 30-40 min from room temperature to $32^{\circ} \mathrm{C}$ and superfused $(1.8-2.0 \mathrm{ml} / \mathrm{min})$ with bath solution containing the following (in $\mathrm{mm}$ ): $125 \mathrm{NaCl}, 26 \mathrm{NaHCO}_{3}$, $3 \mathrm{KCl}, 1.25 \mathrm{NaH}_{2} \mathrm{PO}_{4}, 2.5 \mathrm{CaCl}_{2}, 1.3 \mathrm{MgCl}_{2}, 13$ D-glucose. This solution was continuously bubbled with $95 \% \mathrm{O}_{2} / 5 \% \mathrm{CO}_{2}$ to maintain the $\mathrm{pH}$ at 7.4. Sucrose was used to adjust osmolality to $306-308 \mathrm{mosmol} / \mathrm{kg}$. Slices were allowed to recover $\geq 60 \mathrm{~min}$ before recordings were performed. Medial perforant path (MPP) fibers were selectively stimulated via a bipolar platinum wire electrode $(100 \mu \mathrm{S})$ placed in the middle molecular layer (mML). Field EPSPs (fEPSPs) were recorded in $\mathrm{mML}$ via glass pipettes [borosilicate glass capillaries, 4-7 M , pulled with PP-830 (Narishige, Tokyo, Japan) or PIP5 (HEKA Elektronik, Lambrecht, Germany)] filled with bath solution. All recordings were performed at $32^{\circ} \mathrm{C}$. Stimulation strength was adjusted to half-maximum amplitude of the fEPSP. Analog data were digitized [with Digidata 1322 (Molecular Devices, Menlo Park, CA) or Power1401 (Cambridge Electronic Design, Cambridge, UK)] and stored for off-line analysis [with pCLAMP software (Molecular Devices) or Signal2 (Cambridge Electronic Design )]. To analyze short-term plasticity, we applied 10 stimulations at $1,5,10$, or $20 \mathrm{~Hz}$, and then calculated the ratio of the mean of the eighth to the tenth fEPSP over the first fEPSP ( fEPSP $_{8-10} /$ fEPSP $_{1}$ ). The HCN channel blockers ZD7288 (10 $\mu \mathrm{M}$; Tocris, Cologne, Germany) and zatebradine (20 $\mu \mathrm{M}$; Tocris) were applied for $30 \mathrm{~min}$ to evaluate short-term plasticity during HCN channel blockade. To exclude any contamination with lateral perforant path (LPP)-evoked fEPSPs, the group III metabotropic glutamate receptor agonist L-2-amino-4-phosphonobutyrate (L-AP4; Tocris) was applied at the end of each experiment (Dietrich et al., 1997). Only slices that showed virtually no sensitivity to L-AP4 (depression $<15 \%$ ) and exhibited paired-pulse depression $\left(\mathrm{fEPSP}_{2} / \mathrm{fEPSP}_{1}<95 \%\right)$ were included. Sensitivity to L-AP4 was further used as an indicator for LPPevoked fEPSPs in control experiments that involved LPP stimulation (see Fig. 5d).
Whole-cell patch-clamp recordings. Animals were anesthetized with ketamine hydrochloride and xylazine hydrochloride (intraperitoneally) and perfused via the left cardiac ventricle with 10-20 $\mathrm{ml}$ of ice-cold solution of the following composition (in $\mathrm{mM}$ ): $60 \mathrm{NaCl}, 100$ sucrose, 2.5 $\mathrm{KCl}, 1.25 \mathrm{NaH}_{2} \mathrm{PO}_{4}, 26 \mathrm{NaHCO}_{3}, 1 \mathrm{CaCl}_{2}, 5 \mathrm{MgCl}_{2}, 25$ D-glucose. After perfusion, rats were decapitated, their brains were rapidly removed, and $300 \mu \mathrm{m}$ horizontal slices were cut with a $1000 \mathrm{~S}$ Vibratome (Leica). Slices were stored for $30 \mathrm{~min}$ at $36^{\circ} \mathrm{C}$ in the solution used for perfusion and subsequently maintained in bath solution of the following composition (in mM): $130 \mathrm{NaCl}, 3 \mathrm{KCl}, 1.25 \mathrm{NaH}_{2} \mathrm{PO}_{4}, 25 \mathrm{NaHCO}_{3}, 2 \mathrm{CaCl}_{2}, 1 \mathrm{MgCl}_{2}$, 25 D-glucose, pH 7.4 (room temperature). For recordings, one slice at a time was transferred onto the stage of an upright microscope (Axioskop FS II; Zeiss, Jena, Germany) equipped for infrared differential interference contrast, and, to isolate $I_{\mathrm{h}}$, perfused with a solution $(0.8 \mathrm{ml} / \mathrm{min})$ of the following composition (in mM): $120 \mathrm{NaCl}, 2.5 \mathrm{KCl}, 25 \mathrm{NaHCO}_{3}, 25$ D-glucose, 10 tetraethylammoniumchloride, 2 4-aminopyridine (Fisher Scientific, Loughborough, UK), $2 \mathrm{CaCl}_{2}, 1 \mathrm{MgCl}_{2}, 1 \mathrm{NiCl}_{2}, 0.5 \mathrm{BaCl}_{2}, \mathrm{pH}$ 7.4. In some recordings, $12.5 \mu \mathrm{M}$ 6-cyano-7-nitroquinoxaline-2,3-dione disodium salt (CNQX) and $5 \mu \mathrm{M}$ bicuculline methochloride (Tocris) were added to the perfusing solution to reduce spontaneous synaptic activity. Specificity of $I_{\mathrm{h}}$ was verified by testing sensitivity to ZD7288 (60 $\mu \mathrm{M})$. Recordings were obtained under visual control with borosilicate capillaries (4-7 M $\Omega$ ) filled with a solution containing (in mM): $20 \mathrm{KCl}$, 130 K-gluconate, 10 EGTA, $10 \mathrm{HEPES}, 1 \mathrm{CaCl}_{2}, 3 \mathrm{MgCl}_{2}, 2 \mathrm{Mg}$-ATP, pH 7.25. After obtaining the whole-cell configuration, voltage-clamp recordings were performed with an EPC-9 amplifier (HEKA Elektronik). Data were sampled at $5 \mathrm{kHz}$ and filtered appropriately. Series resistance compensation was used to minimize voltage errors (average series resistance compensation $57 \pm 1.3 \%$, average effective series resistance $6.3 \pm$ $0.4 \mathrm{M} \Omega$ ). $I_{\mathrm{h}}$ was evoked by $2 \mathrm{~s}$ hyperpolarizing pulses from -60 to -130 $\mathrm{mV}$, and current amplitude was determined by subtracting the instantaneous current at the beginning of the voltage step from the sustained component at the end of the pulse. Unless otherwise specified, chemicals were obtained from Sigma.

Data analyses. All analyses were performed blindly (i.e., by an observer unaware of the experimental status of sections or slices). Data acquisition and quantification of in situ hybridization, immunocytochemistry, and Western blots relied on optical density analyses (Brewster et al., 2002, 2007) using the image analysis program ImageTool (version 1.27; The University of Texas Health Science Center, San Antonio, TX). Linearity of hybridization signal was ascertained using ${ }^{14} \mathrm{C}$ standards (American Radiolabeled Chemicals, St. Louis, MO), and data are presented as nanocurie per gram. For analysis of HCN1 immunoreactivity, a linear scale of gray values ( 0 , white; 255 , black) was established as a calibration standard (Grube, 2004). The DG area in sections from TTX-treated and control cultures was photographed, pictures were scanned, and HCN1 signal intensity in the entire molecular layer (ML) was determined. Background levels were measured in the granule cell layer, where HCN1 channel expression is minimal (Bender et al., 2001, 2005), and subtracted. Data are presented as a percentage of control values. Western blots were analyzed as described previously (Brewster et al., 2005, 2007). Data were analyzed using unpaired (in vivo) or paired (in vitro) $t$ tests. Significance levels were set at 0.05 , and data were presented as means with SEs.

\section{Results}

\section{Age-specific localization of HCN1 channels in rodent DG}

Significant quantitative alterations in the expression levels of three HCN channel isoforms ( $\mathrm{HCN} 1, \mathrm{HCN} 2$, and HCN4) in the hippocampus occur during development (Bender et al., 2001; Surges et al., 2006; Brewster et al., 2007), including age-specific onset and termination of expression in specific populations of interneurons and principal cells (Bender et al., 2001, 2005; Brewster et al., 2002, 2007). More recently, localization of these channels in dendritic compartments (Lörincz et al., 2002), where they play major roles (Magee, 1998; Poolos et al., 2002), has been found to vary with age (Brewster et al., 2007). Because the subcellular localization of the HCN channels contributes significantly to their effects on neuronal properties, we focused on ex- 
pression of $\mathrm{HCN}$ channels isoforms within axonal compartments and queried whether it was developmentally regulated. Distinct expression of HCN1 channels occurred in the ML of the DG (Fig. 1), the termination zone of perforant path fibers originating from layer II stellate cells in the $\mathrm{EC}$, and providing the major afferent input to the hippocampal formation (Amaral and Witter, 1995). When the potential subunit composition of the HCN channels in ML was evaluated by immunostaining for other isoforms, no evidence for expression of HCN2 or HCN4 subunits was found, indicating that $\mathrm{HCN}$ expression in the ML selectively involves the HCN1 isoform (Fig. 2c,d).

Time course analysis further revealed that HCN1 channel expression in the ML was age dependent: signal was detected as early as P3, reached a peak during the second postnatal week (Fig. 1 $a, b$ ), then waned with maturation (Fig. $1 c-f$ ). HCN1 distribution was also pathway-selective and confined to the $\mathrm{MML}$, the termination zone of fibers originating in medial EC, whereas outer ML, the termination zone of axons originating in lateral EC, was devoid of HCN1 signal (Fig. 1b).

\section{HCN1 channels localize primarily to perforant path axon terminals}

To examine whether HCN1 channel localization in mML was presynaptic (in perforant path axons) or postsynaptic (in dendrites of DG granule cells or interneurons), we transected the perforant path in a combined entorhinohippocampal organotypic slice culture preparation, in which the perforant path is preserved ( $\mathrm{Li}$ et al., 1994). A strong HCN1-immunoreactive band resided in the ML of cultures that were explanted on $\mathrm{P} 4$ and cultured for $7 \mathrm{~d}$ in vitro (Fig. $3 a, c$ ), similar to the signal in the $\mathrm{P} 11$ in vivo hippocampus (Fig. $1 a, c$ ). Perforant path transection after $4 \mathrm{~d}$ in vitro led to a gradual loss of this band: HCN1immunoreactivity was generally but variably reduced $1 \mathrm{~d}$ after transection (data not shown) and was completely abolished $3 \mathrm{~d}$ after transection (Fig. 3b,d). These data indicate that perforant path integrity is required for the expression (replenishment) of $\mathrm{HCN} 1$ channels in mML and support the notion that the HCN1immunoreactive signal originated in perforant path projection neurons within the EC. However, the data did not exclude the possibility that deafferentation of granule cells resulting from perforant path transection led to postsynaptic downregulation of HCN1 expression in granule cell dendrites.

Therefore, EM was used to pinpoint the location of the HCN1 channels. Fine structural analysis was performed with two different anti-HCN1 antisera (Millipore) (Notomi and Shigemoto, 2004) using pre-embedding silver-enhanced immunogold labeling (Fig. 4a), postembedding immunogold labeling (Fig. 4b), and
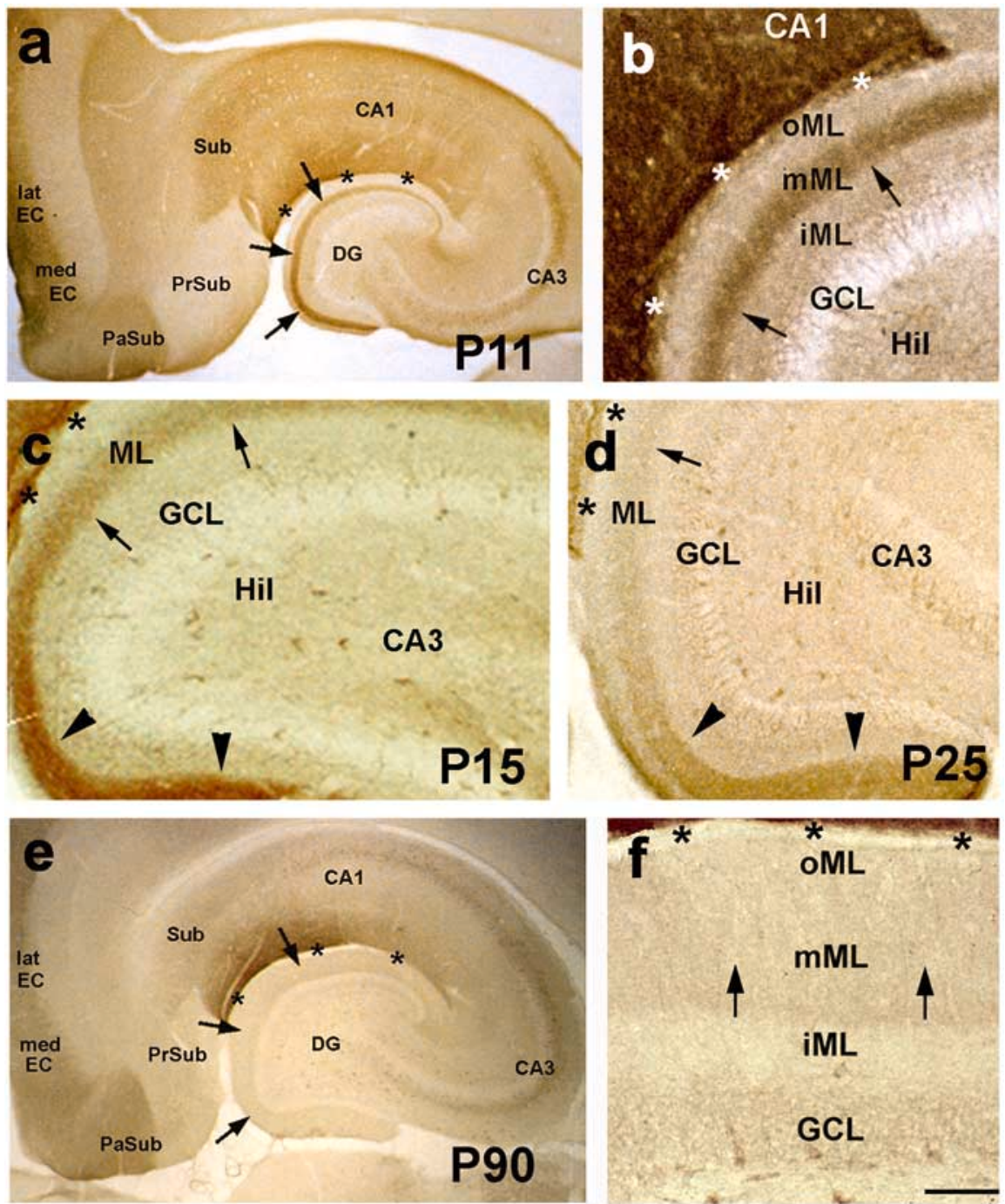

Figure 1. Age-specific and pathway-selective localization of HCN1 channels in the ML of the hippocampal DG. $\boldsymbol{a}$, Horizontal section through the hippocampal formation of an 11-d-old (P11) rat: HCN1 immunoreactivity is found in the ML at this age (arrows); note also the characteristic channel distribution in the dendritic fields of CA1 and subiculum (Sub) (Lörincz et al., 2002; the $\mathrm{mML}$ (arrows), where perforant path fibers deriving from medial (med) EC terminate. Little HCN1 signal was detected in the uter (oML) and inner molecular layer (iML), the termination zones of entorhinal afferents from lateral (lat) EC and DG commis (c, arrows) compared with the signal on P11 (b, arrows). Signal is further reduced on P25 (d, arrow) and is virtually absent on P90 ranule cell layer; Hil, hilus; PaSub, parasubiculum; PrSub, presubiculum. Asterisks denote hippocampal fissure. Scale bar: (in $\boldsymbol{f}$ ) $\boldsymbol{a}$ $e, 400 \mu \mathrm{m} ; \boldsymbol{c}, \boldsymbol{d}, 150 \mu \mathrm{m} ; \boldsymbol{b}, \boldsymbol{f}, 50 \mu \mathrm{m}$.

pre-embedding DAB labeling techniques. In these studies, the majority of HCN1 immunoreactivity was found in axon terminals of the rat perforant path: semiquantitative analysis of gold particle distribution in 35 images $(2 \times 2 \mu \mathrm{m})$ of pre-embedding immunogold-labeled rat ultrathin sections immunostained with the anti-HCN1-antiserum produced by Notomi and Shigemoto (2004) demonstrated that the majority of particles $(\sim 66 \%)$ localized to axon terminals in mML $(26 \%$ at or near the presynaptic membrane, $40 \%$ within axon terminals), whereas a minority of gold particles $(\sim 34 \%)$ was found in postsynaptic structures $(14 \%$ at or near the postsynaptic membrane, $20 \%$ within dendritic spines). The same relative abundance of presynaptic and postsynaptic HCN1 immunoreactivity was observed in DAB-labeled sec- 




Figure 2. HCN1, but not HCN2 or HCN4, channels localize to the ML in immature rats. $\boldsymbol{a}, \boldsymbol{b}$, Antigen specificity of the HCN1 antisera used in this study was tested with tissue from $\mathrm{HCN1}$-deficient $\left(\mathrm{HCN1}^{-1-}\right)$ mice: no $\mathrm{HCN} 1$ immunosignal was detectable in hippocampal sections from these mice (b), whereas the HCN1 pattern in the hippocampus from wild-type (WT; P11) mice resembled that in rats of the corresponding age ( $\boldsymbol{a}$; compare with Fig. 1a). $\boldsymbol{c}$, $\boldsymbol{d}$, Antisera specific for the HCN2 (c) or HCN4 (d) isoform revealed characteristic expression patterns of these isoforms in the P11 rat hippocampus, but no immunoreactivity was detected in the ML (arrows), suggesting that HCN channel expression in the ML is specific for the HCN1 isoform. Hil, Hilus; GCL, granule cell layer; Sub, subiculum; sp, stratum pyramidale. Asterisks denote hippocampal fissure. Arrows in $\boldsymbol{a}$ and $\boldsymbol{b}$ indicate ML. Dashed lines in $\boldsymbol{c}$ and $\boldsymbol{d}$ delineate borders of the GCL. Scale bar (in $\boldsymbol{d}): \boldsymbol{a}, \boldsymbol{b}, 350 \mu \mathrm{m} ; \boldsymbol{c}, \boldsymbol{d}, 100 \mu \mathrm{m}$.
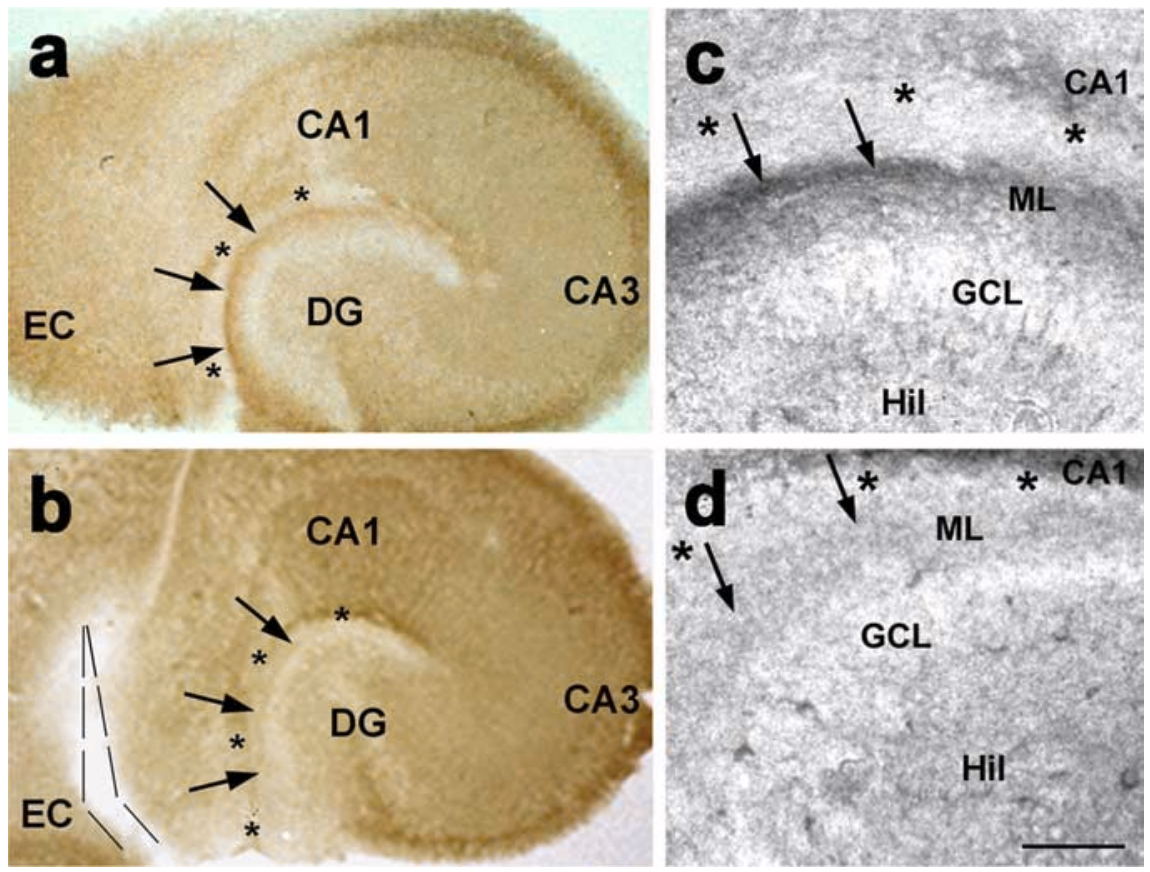

Figure 3. HCN1 channel expression in the ML requires an intact perforant path. $\boldsymbol{a}$, As in P11 rat hippocampus in vivo (Fig. 1a), an HCN1-immunoreactive band resided in the ML (arrows) of combined entorhinohippocampal slice cultures that were explanted on P4 and cultured for $7 \mathrm{~d}$. $\boldsymbol{b}$, Transection of the perforant path in these cultures (after $4 \mathrm{~d}$ in vitro; dashed lines) completely abolished HCN1 immunoreactivity in the ML (arrows), suggesting that perforant path integrity is required for the expression of HCN1 channels in the ML. $\boldsymbol{c}, \boldsymbol{d}$, Higher magnification views of the DG in $\boldsymbol{a}$ and $\boldsymbol{b}$, respectively. GCL, Granule cell layer; Hil, hilus. Asterisks denote hippocampal fissure. Scale bar (in $\boldsymbol{d}$ ): $\boldsymbol{a}, \boldsymbol{c}, 350 \mu \mathrm{m} ; \boldsymbol{b}, \boldsymbol{d}, 50 \mu \mathrm{m}$.

tions of P10 rats. In wild-type mice labeled with the anti-HCN1antiserum from Millipore, the mainly presynaptic expression of HCN1 channels was even clearer, with a ratio between presynaptic and postsynaptic localization of 9:1 (data not shown). Using
HCN1 - / - tissue for a specificity control, only a few randomly distributed gold particles were observed compared with wildtype tissue (data not shown).

We further performed whole-cell patch-clamp recordings from granule cells, to get an estimate of the presence of functional postsynaptic HCN channels. These experiments revealed only low density $I_{\mathrm{h}}$ in granule cells of immature rats (current density, $0.053 \pm 0.011 \mathrm{pA} / \mathrm{pF}$, $n=12$; compared with $1.11 \pm 0.09 \mathrm{pA} / \mathrm{pF}$ in CA1 pyramidal cells, $n=4$ ) (Fig. $4 c$ ), suggesting a rather minor expression of functional postsynaptic channels (although the contribution to $I_{\mathrm{h}}$ of $\mathrm{HCN}$ channels located in dendrites and spines may be underestimated by whole-cellrecordings). Thus, both the anatomical and electrophysiological data suggest that HCN1 channels are predominantly, but not exclusively, expressed in presynaptic elements of the perforant path-granule cell synapse.

\section{Presynaptic HCN channels in the perforant path of developing rats are functional}

To examine whether the HCN1 channels in axon terminals of immature perforant path were functional, we recorded extracellular field potentials from mML of early postnatal and adult rats, in response to stimulation of the MPP at different frequencies. These experiments were performed in the presence or absence of either of two selective $I_{\mathrm{h}}$ blockers, ZD7288 and zatebradine. ZD7288 was used at low concentrations $(10 \mu \mathrm{M})$ that typically do not suppress synaptic activity (Chevaleyre and Castillo, 2002; Gill et al., 2006). We took advantage of the fact that, in contrast to LPP-granule cell synapses, MPP-evoked fEPSPs characteristically exhibit shortterm depression (STD), a form of shortterm plasticity attributed to presynaptic mechanisms (Harris and Cotman, 1985; Dietrich et al., 1997). STD was consistently observed in slices from both early postnatal (P10-P14) (Fig. 5a,b) and adult rats (P50-P80) (Fig. 5c) after MPP stimulation (10 stimuli) at 1, 5, 10, or $20 \mathrm{~Hz}$. Application of ZD7288 to the bath solution modulated this short-term plasticity in a frequency-dependent manner: STD was significantly increased in the presence of ZD7288 at the $20 \mathrm{~Hz}$ stimulation rate fEPSP $_{8-10} / \mathrm{fEPSP}_{1}$ ratio, $48 \pm 3 \%$ in the presence of ZD7288 and $59 \pm 5 \%$ under control conditions; $n=9, p<0.05$, paired $t$ test) (Fig. $5 a, e$ ), but not after stimulation at 1,5 , or $10 \mathrm{~Hz}$ (Fig. $5 a$ ). These findings were confirmed using an additional, structurally distinct $I_{\mathrm{h}}$ blocker, zatebradine $(20 \mu \mathrm{M})$ : at a $20 \mathrm{~Hz}$ stimulation rate, the 
fEPSP $_{8-10} / \mathrm{fEPSP}_{1}$ ratio changed significantly from $60 \pm 4 \%$ in control solution to $52 \pm 3 \%$ in the presence of zatebradine $(n=9, p<0.05$, paired $t$ test) (Fig. $5 b, e)$, whereas no effect was observed at lower frequencies (Fig. 5b). The effects of ZD7288 and zatebradine on STD were age-dependent, and not observed in slices from adult rats at any frequency $(n=$ 6-10) (Fig. 5c,e). No effect of $I_{\mathrm{h}}$ blockers on short-term plasticity was observed when the LPP was stimulated $(n=6)$ (Fig. $5 d)$. These data suggest that functional $I_{\mathrm{h}}$ exists in presynaptic compartments within mML of immature but not adult rats and modulates synaptic transmission in a frequency-dependent manner.

These experiments suggested a novel role for $I_{\mathrm{h}}$ in perforant path-granule cell synapses that is developmentally regulated. Comparing the control bars from P10-P14 rats to those from adults in Figure $5 f$, STD was less pronounced early in life (the $\mathrm{fEPSP}_{8-10} / \mathrm{fEPSP}_{1}$ ratio was $59 \pm$ $3 \%$ in immature compared with $49 \pm 2 \%$ in adult animals; $n=18$ and 12 , respectively; $p<0.05$, unpaired $t$ test). Blocking $I_{\mathrm{h}}$ in immature rats increased STD to adult levels, abolishing its age-specific suppression. This suggests that $I_{\mathrm{h}}$ might contribute to the developmental regulation of this short-term plasticity.

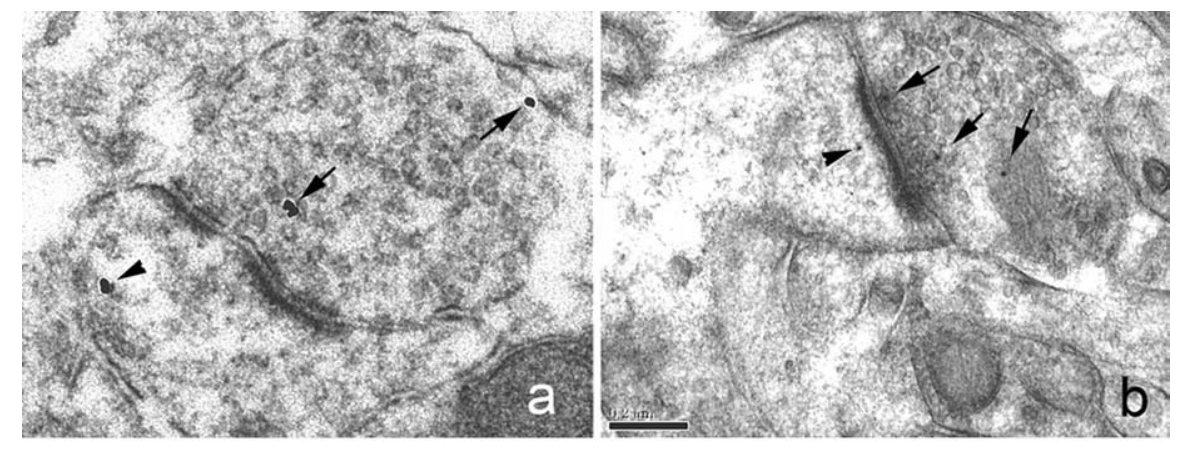

\section{C}

DG

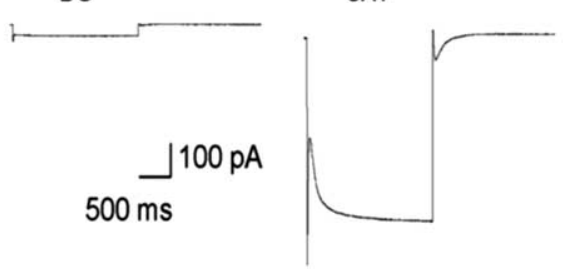

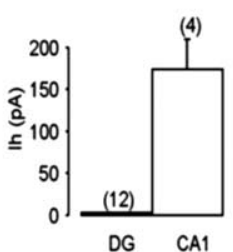

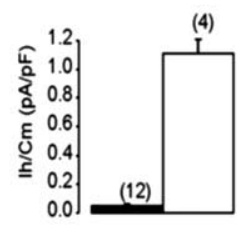

DG

CA1
Figure 4. HCN1 channels localize to perforant path axon terminals. $\boldsymbol{a}, \boldsymbol{b}$, EM analyses using pre-embedding silver intensified immunogold $(\boldsymbol{a})$ and postembbeding immunogold techniques $(\boldsymbol{b})$ identified HCN1 channels predominately in perforant path terminals (arrows) in the middle molecular layer of immature rats (P10). To a lesser extent, HCN1 channels were also detected in postsynaptic structures of dentate granule cells (arrowheads). Scale bar (in $\boldsymbol{b}$ ): $\boldsymbol{a}, 0.4 \mu \mathrm{m} ; \boldsymbol{b}, 0.2 \mu \mathrm{m}$. $\boldsymbol{c}$, Whole-cell patch-clamp recordings illustrate that a $2 \mathrm{~s}$ duration hyperpolarizing pulse from -60 to $-130 \mathrm{mV}$ elicited little $I_{\mathrm{h}}$ in the DG granule cells of immature rats. Note that mean amplitude and current density of $I_{h}$ in granule cells ( $n=12 ; 4$ rats) reached $<5 \%$ of the values detected in (A1 pyramidal cells ( $n=4 ; 3$ rats) at the same age. These data suggest that there is minimal expression of functional $\mathrm{HCN}$ channels in postsynaptic elements of the perforant path-granule cell synapse.

\section{Transient axonal localization of $\mathrm{HCN} 1$ is not a result of age- dependent downregulation of channel expression in the cells of origin}

What could be the basis for the loss of HCN1 expression in the axonal compartment in the perforant path? An obvious candidate mechanism is downregulation of HCN1 mRNA transcription or protein translation in the cells of origin of these axons (the layer II stellate cells of the medial EC) resulting in a reduced HCN1 channel pool available for axonal transport. To test this hypothesis, we examined HCN1 mRNA expression levels in these cells. In situ hybridization analyses using quantitative (Fig. $6 a, b$ ) and single-cell resolution (Fig. $6 d, e$ ) approaches revealed robust HCN1 mRNA signal in layer II stellate cells in both immature (P11) (Fig. 6a,d) and adult (P90) (Fig. 6b,e) medial EC. Quantitative analyses did not find differences between immature and adult HCN1 mRNA expression levels (Fig. $6 c$ ). HCN1 protein levels were also similar in adult and immature medial EC, as measured using Western blots (Fig. 6f,g). Thus, layer II stellate cells of mature rats produced considerable amounts of HCN1 channels, without expression of these channels within the axonal compartment. This suggests that the age-specific axonal expression of HCN1 channels is a result of subcellular trafficking (Deutsch, 2002; Misonou and Trimmer, 2004).

\section{Regulation of presynaptic HCN1 expression involves neuronal activity}

As shown above, HCN1 channel transport to perforant path axons decreases concurrently with the maturation of the perforant path, suggesting a connection between these two processes. Neuronal activity, specifically action-potential firing, has been shown to be indispensable for the differentiation of the perforant pathgranule cell synapses (Frotscher et al., 2000). Therefore, we examined whether the expression of presynaptic HCN1 channels in the perforant path was affected by blockade of neuronal activity, by incubating combined entorhinohippocampal slice cultures (explanted on P4) for $6 \mathrm{~d}$ with or without TTX $(0.1 \mu \mathrm{M})$, suppressing $>95 \%$ of action potentials (Denac et al., 2000). At the end of this treatment, the intensity of $\mathrm{HCN} 1$ immunoreactivity in ML was significantly stronger $(\sim 26 \%)$ in cultures that were chronically exposed to TTX compared with controls $(n=31 ; p=$ 0.02; paired $t$ test) (Fig. $7 a-c$ ). This was not a result of increased expression in the cells of origin, because HCN1 mRNA expression levels in layer II of the medial EC were not altered (Fig. $7 d-f$ ). These data, suggesting increased steady-state levels of HCN1 in mML after chronic blockade of action potentials, support a role for neuronal activity in the developmental regulation of presynaptic HCN1 expression. However, the precise mechanism of this regulation (e.g., whether axonal transport of the channels, channel turnover, or other processes influencing steady-state expression are involved), remains to be determined.

\section{Discussion}

These studies demonstrate a novel type of plasticity of the HCN channels that involves their localization in axons and presynaptic terminals during specific stages of hippocampal development. Specifically, (1) HCN1 channels localize and are likely transported to presynaptic terminals of immature MPP; (2) the presynaptic $\mathrm{HCN}$ channels contribute to age-specific neuronal firing properties; (3) HCN1 expression in perforant path axon terminals, but not HCN1 expression in the cells of origin, declines with 
a Early postnatal MPP (P10-14)
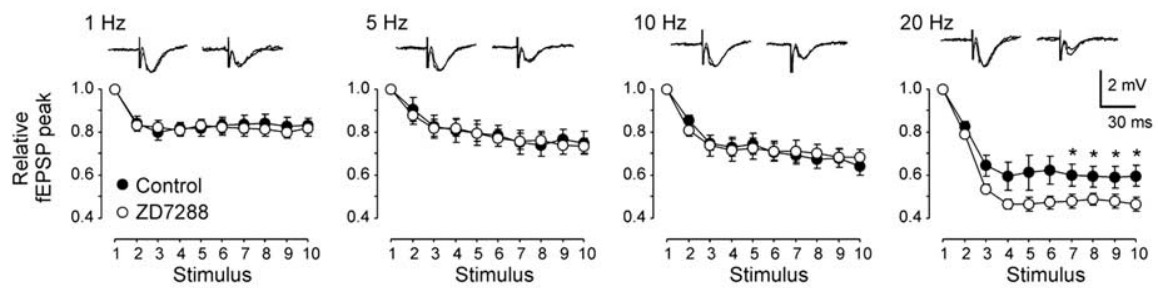

b
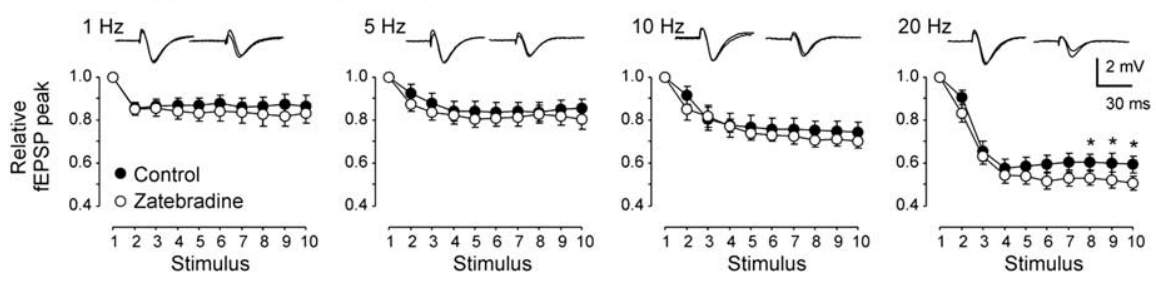

C

Adult MPP (P50-80)
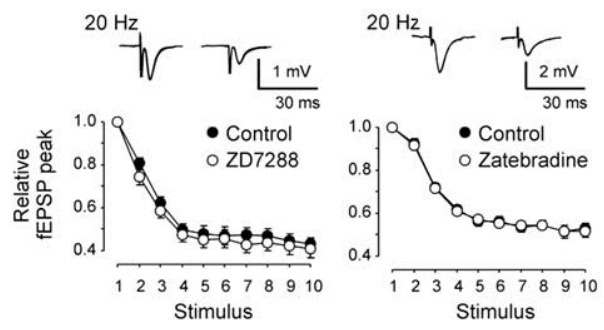

d
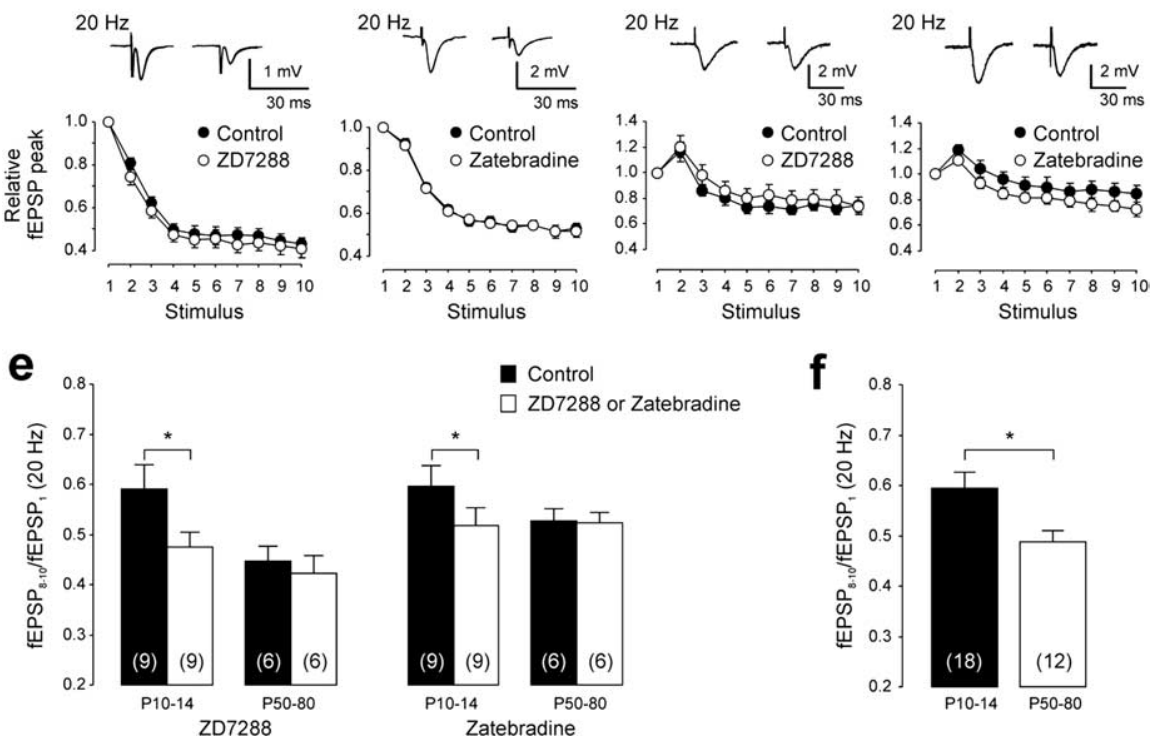

Figure 5. $I_{\mathrm{h}}$ channels in immature perforant path terminals are functional and contribute to synaptic properties. $\boldsymbol{a}, \boldsymbol{b}$, Repetitive stimulation (10 stimuli) of MPP in slices from early postnatal rats (P10-P14) resulted in STD (filled circles) of fEPSP recorded in the $\mathrm{mML}$. Application of $I_{\mathrm{h}}$ channel blockers (open circles) to the bath solution modulated STD in a frequency-dependent manner: STD was increased in the presence of ZD7288 $(10 \mu \mathrm{m} ; \boldsymbol{a})$, and zatebradine $(20 \mu \mathrm{m} ; \boldsymbol{b})$, respectively, when stimuli were given at $20 \mathrm{~Hz}\left({ }^{*} p<0.05\right.$ for both $2 \mathrm{D} 7288$ and zatebradine), but not after stimulation with 1,5, or $10 \mathrm{~Hz}$. c, HCN channel blockade did not affect STD after MPP stimulation in slices from adult rats (P50-P80). $\boldsymbol{d}$, Similarly, $I_{\mathrm{h}}$-blockade did not alter STD in slices from early postnatal rats, when the LPP was stimulated (note the characteristic initial facilitation of LPP-evoked EPSPS). $\boldsymbol{e}, A$ comparison of $\mathrm{EEPS}_{8-10} / \mathrm{fEPSP}_{1}$ ratios after $20 \mathrm{~Hz}$ stimulation of MPP illustrates the age dependency of ZD7288- and zatebradineinduced effects on STD: no difference was observed after $I_{h}$ blockade in the adult slices, suggesting that little $I_{h}$ was activated in adult MPP, consistent with our neuroanatomical data. $f$, In general, STD after $20 \mathrm{~Hz}$ was significantly more pronounced in slices from adult compared with slices from immature rats $\left({ }^{*} p<0.05\right)$. Note that this difference was abolished in the presence of the $I_{h}$ blockers (see $\boldsymbol{e}$ ). Insets in $\boldsymbol{a}-\boldsymbol{d}$ show the first and the tenth control EPSP superimposed with the corresponding EPSP obtained in the presence of $I_{\mathrm{h}}$ blocker.

age; and (4) action potential blockade increases presynaptic $\mathrm{HCN} 1$ expression in immature perforant path, suggesting a regulatory role of neuronal activity. These findings demonstrate a novel, developmentally regulated axonal localization of functional ion channels and suggest a role of HCN1 channelmediated, presynaptic $I_{\mathrm{h}}$ in hippocampal maturation.

HCN channels are highly suitable to contribute to neuronal network maturation that involves changes in intrinsic properties and firing behavior of neurons. Because these neuronal proper- ties are largely determined by the complement of ion channels expressed by a given neuron (Yaari and Beck, 2002; Zhang and Linden, 2003), channels endowed with considerable functional plasticity are particularly suited for this purpose. $\mathrm{HCN}$ channels are gated by both voltage and intracellular ligands (Wang et al., 2002; Frere et al., 2004) permitting a wide range of cellular signals to influence their function (DiFrancesco and Tortora, 1991; Santoro and Baram, 2003; van Welie et al., 2004; Zong et al., 2005; Poolos et al., 2006). Additional, longer-lasting modulation of neuronal HCN channel activity is achieved via regulation of $\mathrm{HCN}$ isoform expression (Bräuer et al., 2001; Brewster et al., 2002, 2005; Santoro and Baram, 2003), subunit heteromerization (Much et al., 2003; Brewster et al., 2005) and, as suggested here, subcellular transport and expression (Brewster et al., 2007).

Several forms of HCN channel plasticity have been found to contribute to the maturation of the hippocampal network. For example, in CA1 pyramidal cells, quantitative changes in $\mathrm{HCN} 1, \mathrm{HCN} 2$, and HCN4 expression constitute a "molecular switch" from an early postnatal preponderance of slow-kinetics cAMPsensitive isoforms (HCN2 and $\mathrm{HCN} 4$ ), to a mature stage in which a major contribution to the properties of $\mathrm{I}_{\mathrm{h}}$ comes from the fast-kinetics cAMP-insensitive HCN1 isoform (Surges et al., 2006; Brewster et al., 2007). This occurs concurrently with a developmental increase of cAMP production in these pyramidal cells, suggesting adaptation of the $I_{\mathrm{h}}$ phenotype to altered cAMP signaling (Surges et al., 2006). In CA3 pyramidal cells, a strong neonatal expression of the HCN1 isoform (Vasilyev and Barish, 2002) might underlie the generation of a giant depolarizing potential, an early network activity (Ben-Ari, 2002; Bender et al., 2005). Network activity, in turn, influences HCN expression levels (Chen et al., 2001; Brewster et al., 2002, 2005), suggesting that the coordinated expression of $\mathrm{HCN}$ channels in the developing hippocampus is part of a developmental program that is regulated by neuronal activity.

The current studies demonstrate a developmentally regulated localization of HCN channels within presynaptic terminals that may contribute to hippocampal maturation. Subcellular localization of these channels influences their functions: dendritic $I_{\mathrm{h}}$ dampens dendritic summation, whereas somatic $I_{\mathrm{h}}$ regulates cellular membrane potential among other roles (Magee, 1998; Poolos et al., 2002; Aponte et al., 2006; for review, see Robinson and Siegelbaum, 2003; Santoro and Baram, 2003), providing impetus for studying mechanisms that regulate subcellular channel transport. The subcellular (including axonal) localization of $\mathrm{HCN}$ 
channels in the hippocampus varies significantly among neuronal populations, indicating that the mechanisms that govern channel transport are neuron specific (Santoro et al., 1997; Notomi and Shigemoto, 2004; Brewster et al., 2007). The present data demonstrate additional complexity of the regulation of subcellular $\mathrm{HCN}$ channel localization, highlighting its temporal (developmental) dimension. Concordant with this notion, an age-dependent localization of HCN2 channels in distal dendrites of CA1 pyramidal cells has recently been reported (Brewster et al., 2007).

The function of the HCN1 channels localized to presynaptic terminals of the immature perforant path is not fully elucidated by the current studies. Synaptic transmission in the MPP is characterized by frequency-dependent STD (Harris and Cotman, 1985; Dietrich et al., 1997) that is less pronounced in early development compared with the mature hippocampus (Fig. 5f). Blocking $I_{\mathrm{h}}$ increased STD in the immature MPP to values indistinguishable from those of adults and did not alter frequency-dependent properties of adult synapses. These findings suggest that $I_{\mathrm{h}}$ might function to increase reliability of neuronal firing by exerting a tonic presynaptic depolarizing influence (Beaumont and Zucker, 2000; Southan et al., 2000), as suggested for presynaptic $I_{\mathrm{h}}$ in fast-spiking hippocampal basket cells (Aponte et al., 2006). For nascent perforant path-granule cell synapses, reliability of neuronal firing may be a prerequisite for stabilization and maturation of the synaptic contact (Frotscher et al., 2000), specifically during the developmental period when the axons are not yet myelinated (myelination occurs in the perforant path from P15-P60) (Meier et al., 2004). It should be noted that a minority of the HCN1 channels in mML $(\sim 30 \%)$ were postsynaptic, localizing to spines and dendrites. A contribution of these channels to the observed $I_{\mathrm{h}}$ effects on STD cannot be excluded, but seems unlikely, given the small magnitude of $I_{\mathrm{h}}$ recorded postsynaptically, and the established actions of dendritic $I_{\mathrm{h}}$ to reduce excitability (Magee, 1998; Poolos et al., 2002) rather than to promote neuronal firing as shown here (Fig. 5). The functions of the postsynaptic HCN channels, as well as the reasons for their disappearance with maturation, are currently unknown. However, it could be speculated that a postsynaptic reduction of neuronal excitability is critical for granule cells, specifically in immature DG, where GABAergic inhibition is not yet fully established (Hollrigel and Soltesz, 1997).

A remarkable observation in the present study was that $\mathrm{HCN} 1$ localized selectively to axon terminals of the medial, but not lateral, perforant path. Neurons contributing to this pathway are $\mu \mathrm{m} ; \boldsymbol{e}, 60 \mu \mathrm{m}$. $d, e, 400 \mu \mathrm{m}$.
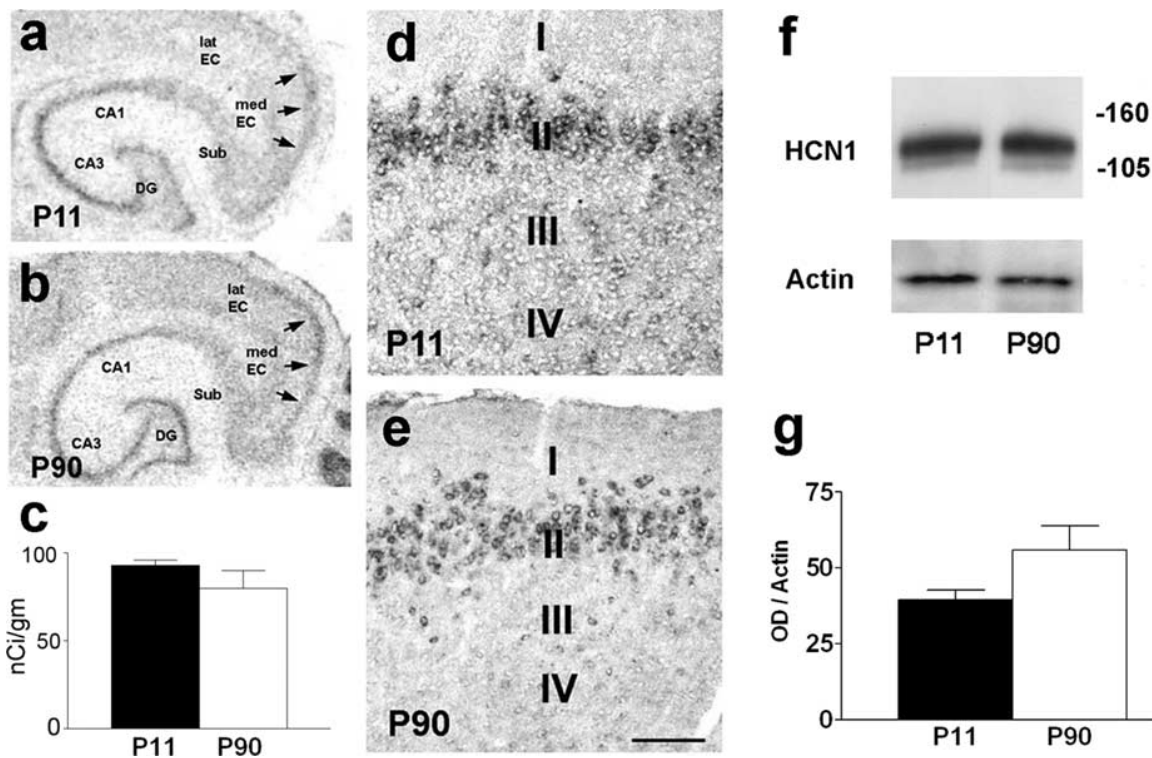

Figure 6. HCN1 expression is not downregulated with age in the EC layer Il stellate cells, the cells of origin of perforant path. $\boldsymbol{a}-\boldsymbol{c}$, In situ hybridization (ISH) using $\mathrm{S}^{35}$-labeled probes indicated expression of HCN1 mRNA in layer II of the medial (med) EC (arrows) in both immature (P11; $\boldsymbol{a})$ and adult rat $(\mathrm{P} 90 ; \boldsymbol{b})$, and quantitative analysis of radioactive ISH-signal suggested that expression levels were not different at these ages $(\boldsymbol{c})$. $\boldsymbol{d}, \boldsymbol{e}$, Single-cell resolution ISH using digoxigenin-labeled probes demonstrated that layer II stellate cells expressed HCN1 mRNA robustly in both immature $(\boldsymbol{d})$ and adult medial EC $(\boldsymbol{e}) . \boldsymbol{f}, \boldsymbol{g}$, Representative Western blots $(\boldsymbol{f})$ and quantitative analysis of HCN1 protein levels (relative to actin, $\boldsymbol{g}$ ) further confirmed that HCN1 expression was not decreased in adult compared with immature medial EC. Sub, Subiculum; lat EC, lateral EC. Scale bar (in $\boldsymbol{e}$ ): $\boldsymbol{a}, \boldsymbol{b}, 500 \mu \mathrm{m} ; \boldsymbol{d}, 50$
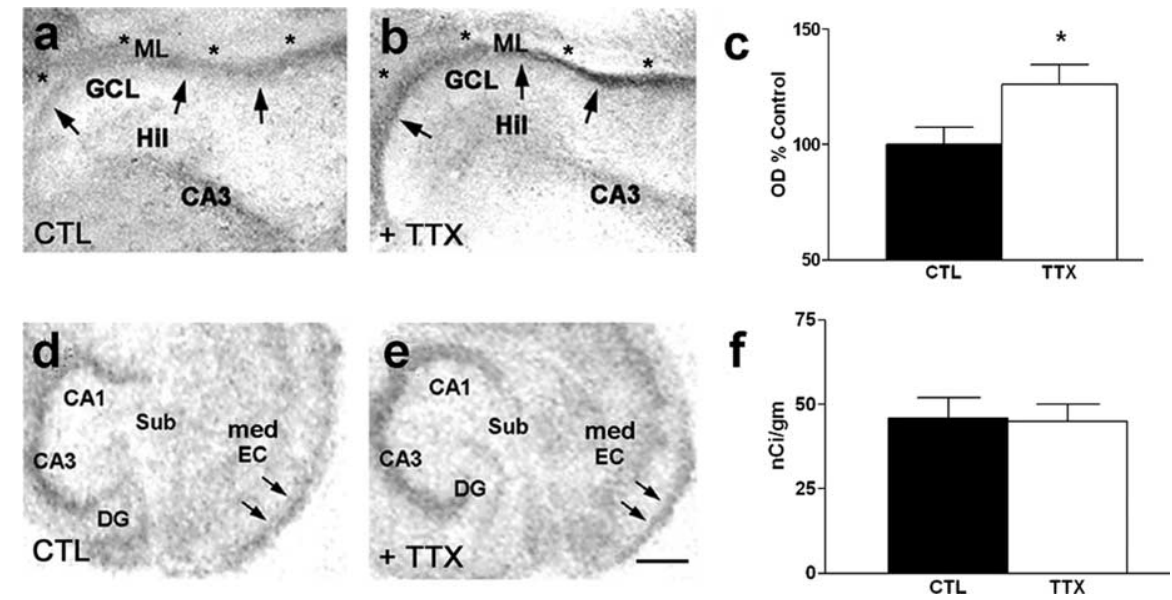

Figure 7. HCN1 expression in the ML is regulated by neuronal activity. $\boldsymbol{a}-\boldsymbol{c}$, To examine whether neuronal activity influences expression of HCN1 in the ML, combined entorhinohippocampal slices (P4 explanted; 7 in vitro) were incubated from day 2 to day 7 in vitro with $0.1 \mu \mathrm{M}$ TTX in the culture medium. TTX treatment resulted in a significant ( 26\%) increase of HCN1 immunoreactivity in the ML (measured as optical density) compared with untreated sister cultures $\left(\boldsymbol{c}\right.$; $\left.{ }^{*} p=0.02\right)$. $\boldsymbol{d}-\boldsymbol{f}$, HCN1 mRNA expression in layer II of the medial EC (med EC, arrows) was not altered in TTX-treated (e) compared with untreated $(\boldsymbol{d}, \boldsymbol{f})$ cultures, indicating that the stronger HCN1 signal in the ML after TTX treatment was not the result of increased HCN1 expression in the cells of origin. GCL, Granule cell layer; Hil; hilus; Sub, subiculum. Asterisks denote hippocampal fissure. Scale bar (in $\boldsymbol{e}$ ): $\boldsymbol{a}, \boldsymbol{b}, 100 \mu \mathrm{m}$;

capable of generating action potential firing up to the gamma frequency range (Chrobak and Buzsaki, 1998; van der Linden et al., 1999). Interestingly, together with Aponte et al. (2006), the current data localizes HCN1 to axon terminals of two different populations of fast-spiking neurons. This suggests that these channels may contribute to the stability of oscillations at higher frequencies (Aponte et al., 2006). This notion is further supported by our finding of frequency-dependent activation $(>10$ $\mathrm{Hz}$ ) of $I_{\mathrm{h}}$ in axon terminals of the MPP. 
The regulation of $\mathrm{HCN} 1$ channel expression in perforant path axons and terminals likely involves post-translational mechanisms, although local axonal translation cannot be excluded. Post-translational modifications of HCN channels are poorly understood. N-glycosylation is critical for subcellular trafficking and membrane insertion of $\mathrm{HCN}$ channels in heterologous systems (Much et al., 2003), but neuronal mechanisms might differ (Zha et al., 2006). HCN channel phosphorylation should also be considered, because this modification has been reported (Zong et al., 2005; Poolos et al., 2006) and is known to regulate the subcellular localization of a potassium channel (Kv2.1) in an activitydependent manner (Misonou et al., 2004). In addition to modifications of HCN channels themselves, subcellular transport might involve interaction of the channel with other proteins, such as the Rab8b-interacting protein TRIP8b (Santoro et al., 2004) or specific components of the cytoskeleton (Gravante et al., 2004).

In conclusion, we demonstrate a novel, age-regulated localization of HCN channels in axons and terminals of the key afferent pathway to the hippocampus. This transient expression (transport) of HCN channel suggests that presynaptic $I_{\mathrm{h}}$ may be required during a specific stage of the development of this pathway, contributing to its maturation. In addition, we propose that plasticity of subcellular HCN channel localization may be a general mechanism that may also operate under pathological conditions (Bender et al., 2003; Kamal et al., 2006).

\section{References}

Agmon A, Wells JE (2003) The role of the hyperpolarization-activated cationic current $I_{\mathrm{h}}$ in the timing of interictal bursts in the neonatal hippocampus. J Neurosci 23:3658-3668.

Amaral DG, Witter MP (1995) The hippocampal formation. In: The rat nervous system, Ed 2. (Paxinos G, ed), pp 443-494. New York: Academic.

Aponte Y, Lien C, Reisinger E, Jonas P (2006) Hyperpolarization-activated cation channels in fast-spiking interneurons of rat hippocampus. J Physiol (Lond) 574:229-243.

Beaumont V, Zucker RS (2000) Enhancement of synaptic transmission by cyclic AMP modulation of presynaptic $I_{h}$ channels. Nat Neurosci 3:133-141.

Ben-Ari Y (2002) Excitatory actions of GABA during development: the nature of the nurture. Nat Rev Neurosci 3:728-739.

Bender RA, Brewster AL, Santoro B, Ludwig A, Hofmann F, Biel M, Baram TZ (2001) Differential and age-dependent expression of hyperpolarizationactivated, cyclic nucleotide-gated cation channel isoforms 1-4 suggests evolving roles in the developing rat hippocampus. Neuroscience 106:689-698.

Bender RA, Soleymani SV, Brewster AL, Nguyen ST, Beck H, Mathern GW, Baram TZ (2003) Enhanced expression of a specific hyperpolarizationactivated cyclic nucleotide-gated cation channel $(\mathrm{HCN})$ in surviving dentate gyrus granule cells of human and experimental epileptic hippocampus. J Neurosci 23:6826-6836.

Bender RA, Galindo R, Mameli M, Gonzalez-Vega R, Valenzuela CF, Baram TZ (2005) Synchronized network activity in developing rat hippocampus involves regional hyperpolarization-activated cyclic nucleotide gated (HCN) channel function. Eur J Neurosci 2:2667-2674.

Bräuer AU, Savaskan NE, Kole MH, Plaschke M, Monteggia LM, Nestler EJ, Simburger E, Deisz RA, Ninnemann O, Nitsch R (2001) Molecular and functional analysis of hyperpolarization-activated pacemaker channels in the hippocampus after entorhinal cortex lesions. FASEB J 15:2689-2701.

Brewster AL, Bender RA, Chen Y, Dubé C, Eghbal-Ahmadi M, Baram TZ (2002) Developmental febrile seizures modulate hippocampal gene expression of hyperpolarization-activated channels in an isoform and cellspecific manner. J Neurosci 22:4591-4599.

Brewster AL, Bernard JA, Gall CM, Baram TZ (2005) Formation of heteromeric hyperpolarization-activated cyclic nucleotide-gated (HCN) channels in the hippocampus is regulated by developmental seizures. Neurobiol Dis 19:200-207.

Brewster AL, Chen Y, Bender RA, Yeh A, Shigemoto R, Baram TZ (2007)
Quantitative analysis and subcellular distribution of mRNA and protein expression of the hyperpolarization-activated cyclic nucleotide-gated channels throughout development in rat hippocampus. Cereb Cortex 17:702-712.

Chen K, Aradi I, Thon N, Eghbal-Ahmadi M, Baram TZ, Soltesz I (2001) Persistently modified h-channels after complex febrile seizures convert the seizure-induced enhancement of inhibition to hyperexcitability. Nat Med 7:331-337.

Chen Y, Bender RA, Brunson KL, Pomper J, Grigoriadis DE, Wurst W, Baram TZ (2004) Modulation of dendritic differentiation by corticotropinreleasing factor in the developing hippocampus. Proc Natl Acad Sci USA 101:15782-15787.

Chevaleyre V, Castillo PE (2002) Assessing the role of $\mathrm{I}_{\mathrm{h}}$ channels in synaptic transmission and mossy fiber LTP. Proc Natl Acad Sci USA 99:9538-9543.

Chrobak JJ, Buzsaki G (1998) Gamma oscillations in the entorhinal cortex of the freely behaving rat. J Neurosci 18:388-398.

Constantine-Paton M, Cline HT (1998) LTP and activity-dependent synaptogenesis: the more alike they are, the more different they become. Curr Opin Neurobiol 8:139-148.

Denac H, Mevissen M, Scholtysik G (2000) Structure, function and pharmacology of voltage-gated sodium channels. Naunyn Schmiedebergs Arch Pharmacol 362:453-479.

Deutsch C (2002) Potassium channel ontogeny. Annu Rev Physiol 64:19-46.

Dietrich D, Beck H, Kral T, Clusmann H, Elger CE, Schramm J (1997) Metabotropic glutamate receptors modulate synaptic transmission in the perforant path: pharmacology and localization of two distinct receptors. Brain Res 767:220-227.

DiFrancesco F, Tortora P (1991) Direct activation of cardiac pacemaker channels by intracellular cyclic AMP. Nature 351:145-147.

Förster E, Zhao S, Frotscher M (2006) Laminating the hippocampus. Nat Neurosci Rev 7:259-267.

Frere SG, Kuisle M, Lüthi A (2004) Regulation of recombinant and native hyperpolarization-activated cation channels. Mol Neurobiol 30:279-305.

Frotscher M, Drakew A, Heimrich B (2000) Role of afferent innervation and neuronal activity in dendritic development and spine maturation of fascia dentata granule cells. Cereb Cortex 10:946-951.

Galvan CD, Wenzel JH, Dinsley KT, Lam TT, Schwartzkroin PA, Sweatt JD, Swann JW (2003) Postsynaptic contributions to hippocampal network hyperexcitability induced by chronic activity blockade in vivo. Eur J Neurosci 18:1861-1872.

Gill CH, Brown JT, Shivji N, Lappin SC, Farmer C, Randall A, McNaughton NC, Cobb SR, Davies CH (2006) Inhibition of Ih reduces epileptiform activity in rodent hippocampal slices. Synapse 59:308-316.

Gravante B, Barbuti A, Milanesi R, Zappi I, Viscomi C, Di Francesco D (2004) Interaction of the pacemaker channel HCN1 with filamin A. J Biol Chem 279:43847-43853.

Grube D (2004) Constants and variables in immunohistochemistry. Arch Histol Cytol 67:115-134.

Harris EW, Cotman CW (1985) Effects of synaptic antagonists on perforant path paired-pulse plasticity: differentiation of pre- and postsynaptic antagonism. Brain Res 334:348-353.

Hollrigel GS, Soltesz I (1997) Slow kinetics of miniature IPSCs during early postnatal development in granule cells of the dentate gyrus. J Neurosci 17:5119-5128.

Kamal A, Notenboom RG, de Graan PN, Ramakers GM (2006) Persistent changes in action potential broadening and the slow afterhyperpolarization in rat CA1 pyramidal cells after febrile seizures. Eur J Neurosci 23:2230-2234.

Kaupp UB, Seifert R (2001) Molecular diversity of pacemaker ion channels. Annu Rev Physiol 63:235-257.

Knoll B, Kretz O, Fiedler C, Alberti S, Schütz G, Frotscher M, Nordheim A (2006) Serum response factor controls neuronal circuit assembly in the hippocampus. Nat Neurosci 9:195-204.

Li D, Field PM, Yoshioka N, Raisman G (1994) Axons regenerate with correct specificity in horizontal slice culture of the postnatal rat entorhinohippocampal system. Eur J Neurosci 6:1026-1037.

Liu M, Pleasure SJ, Collins AE, Noebels JL, Naya FJ, Tsai MJ, Lowenstein DH (2000) Loss of BETA2/NeuroD leads to malformation of the dentate gyrus and epilepsy. Proc Natl Acad Sci USA 97:865-870.

Lörincz A, Notomi T, Tamas G, Shigemoto R, Nusser Z (2002) Polarized 
and compartment-dependent distribution of $\mathrm{HCN} 1$ in pyramidal cell dendrites. Nat Neurosci 5:1185-1193.

Lupica CR, Bell JA, Hoffman AF, Watson PL (2001) Contribution of the hyperpolarization-activated current $\left(\mathrm{I}_{\mathrm{h}}\right)$ to membrane potential and GABA release in hippocampal interneurons. J Neurophysiol 86:261-268.

Maccaferri G, McBain CJ (1996) The hyperpolarization-activated current $\left(\mathrm{I}_{\mathrm{h}}\right)$ and its contribution to pacemaker activity in rat CAl hippocampal stratum oriens-alveus interneurons. J Physiol (Lond) 497:119-130.

Magee JC (1998) Dendritic hyperpolarization-activated currents modify the integrative properties of hippocampal CA1 pyramidal neurons. J Neurosci 18:7613-7624.

Meier S, Bräuer AU, Heimrich B, Nitsch R, Savaskan NE (2004) Myelination in the hippocampus during development and following lesion. Cell Mol Life Sci 61:1082-1094.

Misonou H, Trimmer JS (2004) Determinants of voltage-gated potassium channel surface expression and localization in Mammalian neurons. Crit Rev Biochem Mol Biol 39:125-145.

Misonou H, Mohapatra DP, Park EW, Leung V, Zhen D, Misonou K, Anderson AE, Trimmer JS (2004) Regulation of ion channel localization and phosphorylation by neuronal activity. Nat Neurosci 7:711-718.

Much B, Wahl-Schott C, Zong X, Schneider A, Baumann L, Moosmang S, Ludwig A, Biel M (2003) Role of subunit heteromerization and $\mathrm{N}$-linked glycosylation in the formation of functional hyperpolarization-activated cyclic nucleotide-gated channels. J Biol Chem 278:43781-43786.

Nolan M, Malleret G, Dudman JT, Buhl DL, Santoro B, Gibbs E, Vronskaya S, Buzsaki G, Siegelbaum SA, Kandel ER, Morozov A (2004) A behavioral role for dendritic integration: $\mathrm{HCN} 1$ channels constrain spatial memory and plasticity at inputs to distal dendrites of CA1 pyramidal neurons. Cell 119:719-732.

Notomi T, Shigemoto R (2004) Immunohistochemical localization of Ih channel subunits, HCN1-4, in the rat brain. J Comp Neurol 471:241-276.

Poolos NP, Migliore M, Johnston D (2002) Pharmacological up-regulation of h-channels reduces the excitability of pyramidal neuron dendrites. Nat Neurosci 5:767-774.

Poolos NP, Bullis JP, Roth MK (2006) Modulation of h-channels in hippocampal pyramidal neurons by $\mathrm{p} 38$ mitogen-activated protein kinase. J Neurosci 26:7995-8003.

Robinson RB, Siegelbaum SA (2003) Hyperpolarization-activated cation currents: from molecules to physiological function. Annu Rev Physiol 65:453-480.

Santoro B, Baram TZ (2003) The multiple personalities of h-channels. Trends Neurosci 26:550-554.

Santoro B, Grant SGN, Bartsch D, Kandel ER (1997) Interactive cloning with the $\mathrm{SH} 3$ domain of $\mathrm{N}$-src identifies a new brain specific ion channel protein, with homology to Eag and cyclic nucleotide-gated channels. Proc Natl Acad Sci USA 94:14815-14820.

Santoro B, Wainger BJ, Siegelbaum SA (2004) Regulation of HCN channel surface expression by a novel C-terminal protein-protein interaction. J Neurosci 24:10750-10762.

Skutella T, Nitsch R (2001) New molecules for hippocampal development. Trends Neurosci 24:107-113.

Soleng AF, Chiu K, Raastad M (2003) Unmyelinated axons in the rat hippocampus hyperpolarize and activate an $\mathrm{H}$ current when spike frequency exceeds $1 \mathrm{~Hz}$. J Physiol (Lond) 552:459-470.

Southan AP, Morris NP, Stephens GJ, Robertson B (2000) Hyperpolarization-activated currents in presynaptic terminals of mouse cerebellar basket cells. J Physiol (Lond) 526:91-97.

Stoppini L, Buchs PA, Muller D (1991) A simple method for organotypic cultures of nervous tissue. J Neurosci Methods 37:173-182.

Surges R, Brewster AL, Bender RA, Beck H, Feuerstein TJ, Baram TZ (2006) Regulated expression of HCN channels and cAMP levels shape the properties of the h-current in developing rat hippocampus. Eur J Neurosci 24:94-104.

van der Linden S, Panzica F, de Curtis M (1999) Carbachol induces fast oscillations in the medial but not in the lateral entorhinal cortex of the isolated guinea pig brain. J Neurophysiol 82:2441-2450.

van Welie I, van Hooft JA, Wadman WJ (2004) Homeostatic scaling of neuronal excitability by synaptic modulation of somatic hyperpolarizationactivated Ih channels. Proc Natl Acad Sci USA 101:5123-5128.

Vasilyev DV, Barish ME (2002) Postnatal development of the hyperpolarization-activated excitatory current $I_{\mathrm{h}}$ in mouse hippocampal pyramidal neurons. J Neurosci 22:8992-9004.

Wang J, Chen S, Nolan MF, Siegelbaum SA (2002) Activity-dependent regulation of HCN pacemaker channels by cyclic AMP: signaling through dynamic allosteric coupling. Neuron 36:451-461.

Yaari Y, Beck H (2002) "Epileptic neurons" in temporal lobe epilepsy. Brain Pathol 12:234-239.

Zha Q, Brewster AL, Richichi C, Bender RA, Dube C, Baram TZ (2006) Neuronal activity regulates the glycosylation state of the hyperpolarization-activated cyclic nucleotide-gated (HCN1) channel subunit. Soc Neurosci Abstr 32:334.9.

Zhang W, Linden DJ (2003) The other side of the engram: experiencedriven changes in neuronal intrinsic excitability. Nat Neurosci Rev 4:885-900.

Zong X, Eckert C, Yuan H, Wahl-Schott C, Abicht H, Fang L, Li R, Mistrik P, Gerstner A, Much B, Baumann L, Michalakis S, Zeng R, Chen Z, Biel M (2005) A novel mechanism of modulation of hyperpolarizationactivated cyclic nucleotide-gated channels by Src kinase. J Biol Chem 280:34224-34232. 